\title{
Satellite tracking reveals habitat use by juvenile green sea turtles Chelonia mydas in the Everglades, Florida, USA
}

\author{
Kristen M. Hart ${ }^{1, *}$, Ikuko Fujisaki $^{2}$ \\ ${ }^{1}$ US Geological Survey, Southeast Ecological Science Center, 3205 College Avenue, Davie, Florida 33314, USA \\ ${ }^{2}$ University of Florida, Fort Lauderdale Research and Education Center, 3205 College Avenue, Davie, Florida 33314, USA
}

\begin{abstract}
We tracked the movements of 6 juvenile green sea turtles captured in coastal areas of southwest Florida within Everglades National Park (ENP) using satellite transmitters for periods of 27 to $62 \mathrm{~d}$ in 2007 and 2008 (mean \pm SD: $47.7 \pm 12.9 \mathrm{~d}$ ). Turtles ranged in size from 33.4 to $67.5 \mathrm{~cm}$ straight carapace length $(45.7 \pm 12.9 \mathrm{~cm})$ and 4.4 to $40.8 \mathrm{~kg}$ in mass $(16.0 \pm 13.8 \mathrm{~kg})$. These data represent the first satellite tracking data gathered on juveniles of this endangered species at this remote study site, which may represent an important developmental habitat and foraging ground. Satellite tracking results suggested that these immature turtles were resident for several months very close to capture and release sites, in waters from 0 to $10 \mathrm{~m}$ in depth. Mean home range for this springtime tracking period as represented by minimum convex polygon (MCP) was $1004.9 \pm 618.8 \mathrm{~km}^{2}(\mathrm{range}$ 374.1 to $2060.1 \mathrm{~km}^{2}$ ), with 4 of 6 individuals spending a significant proportion of time within the ENP boundaries in 2008 in areas with dense patches of marine algae. Core use areas determined by $50 \%$ kernel density estimates (KDE) ranged from 5.0 to $54.4 \mathrm{~km}^{2}$, with a mean of $22.5 \pm 22.1 \mathrm{~km}^{2}$. Overlap of $50 \% \mathrm{KDE}$ plots for 6 turtles confirmed use of shallow-water nearshore habitats $\leq 0.6 \mathrm{~m}$ deep within the park boundary. Delineating specific habitats used by juvenile green turtles in this and other remote coastal areas with protected status will help conservation managers to prioritize their efforts and increase efficacy in protecting endangered species.
\end{abstract}

KEY WORDS: Chelonia mydas $\cdot$ Green turtle $\cdot$ Everglades $\cdot$ Satellite telemetry $\cdot$ Satellite tracking Home range $\cdot$ Kernel density $\cdot$ Endangered species

\section{INTRODUCTION}

Green sea turtles Chelonia mydas are found in tropical and subtropical marine and coastal environments. Once hatchlings leave the beach, they begin an oceanic phase, perhaps passively floating in major currents or gyres for several years (Carr \& Meylan 1980, Carr 1987). These young turtles then recruit from oceanic habitats to neritic developmental habitats rich in seagrass or marine algae where they forage and grow to maturity (Bjorndal 1980, Musick \& Limpus 1997).

Whereas the ecology and movements of nesting adult Chelonia mydas are reasonably well studied (see Godley et al. 2008 for a review), relatively little is known about the habitat needs and movements of juveniles of this endangered species. In previous satellite tracking studies of juvenile green turtles, Godley et al. (2003) focused on describing movements of 8 fishery-caught turtles off the coast of Brazil, and Pelletier et al. (2003) compared oceanic movements of 2 displaced wild and 4 captive-reared turtles in the Indian Ocean. Both of these satellite tracking studies were conducted outside US waters and both involved animals that spent at least some time (i.e. hours to hundreds of days) in captivity. In contrast, McClellan \& Read (2009) tracked movements and habitat use of 10 wild juvenile green turtles to determine how turtle behavior and site fidelity affected their vulnerability to 
incidental captures in an artisanal gill net fishery in North Carolina.

Despite the low number of satellite tracking studies on immature greens, several studies are available for comparison in which home ranges of immature turtles were quantified using radio and ultrasonic telemetry (Table 1). Overall, most studies have been relatively short in duration and have documented nearshore coastal habitat use and residence patterns. To date, McClellan \& Read (2009) obtained the maximum tracking duration (154 d) for any juvenile green turtle tracking study using telemetry. However, home ranges were remarkably comparable across all studies of juvenile greens, regardless of method (Table 1).

Because satellite tags have become smaller and thus more suitable for use on juvenile sea turtles, we sought to use satellite tracking to characterize movement and residence patterns of juvenile greens observed in remote, difficult to access areas of Everglades National Park (ENP), Florida, USA. The Everglades is the largest subtropical wilderness in the USA, and it contains many species of both rare and endangered flora and fauna. Designated as a World Heritage Site, an International Biosphere Reserve, and a Wetland of International Importance, ENP harbors much neritic foraging habitat and shallow-water refuge sites that may be particularly suitable for juvenile green turtles.

Chelonia mydas can generally be found throughout the entire Atlantic Ocean. The species is listed as Endangered by the International Union for the Conservation of Nature (IUCN) (Groombridge 1982) and threatened under the US Endangered Species Act (ESA) in all areas, except for breeding populations in Florida and on the Pacific coast of Mexico, which are listed as endangered (NMFS \& USFWS 1991). The major nesting sites for Atlantic green turtles can be found on continental beaches and islands throughout the Caribbean coast of Central America, the eastern coast of the South American continent, and on isolated islands in the North Atlantic. The east coast of Florida has the largest breeding assemblage of green turtles in the USA.

Chelonia mydas feeding grounds are widely distributed throughout the region. Such developmental habitats are important for the survival of juvenile marine turtles and the recovery of depleted stocks (Bjorndal et al. 2003, Kubis et al. 2009). Foraging areas for the species in the Atlantic and in Florida specifically include Indian River Lagoon, Palm Beach and St. Lucie Counties, the Florida Keys, Florida Bay, Homosassa, Crystal River, and Cedar Key (Mendonça 1983, Ehrhart \& Redfoot 1992, Schmid 1998, Bresette et al. 1991, Bresette \& Gorham 2001, Witzell \& Schmid 2004, Makowski et al. 2006, Ehrhart et al. 2007). Previously, Schmid (1998) characterized Cedar Key turtles in a study spanning
1986 to 1995 at a site $463 \mathrm{~km}$ to the north of our sampling location, and Witzell \& Schmid (2004) worked $71 \mathrm{~km}$ to the north and documented juvenile green turtles around the Ten Thousand Islands. Other studies including juvenile green turtles in Florida sampled at sites farther from our study site (e.g. St. Lucie County, Bresette et al. 1998; Brevard and Volusia Counties in East Central Florida, Mendonça 1983; Palm Beach County, Makowski et al. 2006).

Information on the spatial biology of marine turtles can reveal variability in life history strategies among disparate subpopulations (Bolten 2003). Moreover, because green turtles spend a vast majority of their lives in coastal foraging and developmental habitats (Musick \& Limpus 1997, Plotkin 2003), where susceptibility to human impacts is often very high (e.g. Groombridge \& Luxmoore 1989, Campbell 2005), understanding their movement patterns in protected areas such as US National Parks may be considered a priority for ongoing conservation efforts and federal recovery plans. Thus, we used satellite telemetry to track juvenile green turtles in the southwest coastal Everglades, a developmental habitat not previously investigated.

Previous research has shown that by establishing a home range, juvenile green turtles enhance their access to resources that offer the most benefit for their growth to sexual maturity (Limpus \& Walter 1980, Limpus et al. 1994, Makowski et al. 2006). Thus, our goals were to (1) measure the seasonal home range of juvenile green turtles in our study site using both minimum convex polygon (MCP; Burt 1943, Mohr 1947) and kernel density estimation (KDE) methods (White \& Garrott 1990, Seaman \& Powell 1996), (2) determine the proportion of area used in ENP, and whether the turtles displayed resident behavior during the tracking period, (3) determine whether turtles showed an affinity to any specific core areas, and (4) describe patterns of overlap among the turtles' home ranges or core areas of activity.

With an understanding of these movement patterns and habitat use, resource managers will be better able to prioritize their efforts to protect all life stages of endangered species using ENP. The Comprehensive Everglades Restoration Plan (CERP; US Army Corps of Engineers and South Florida Water Management District 2004), initiated in 2000, has a goal of restoring the hydrological characteristics of the Everglades while simultaneously meeting the water needs of south Florida's urban and natural areas. The CERP is vital to reducing ecosystem and species vulnerability to stressors associated with future climate change and sea level rise. Monitoring species protected under the US ESA is a major component of the adaptive management framework of the plan; our study will help to 


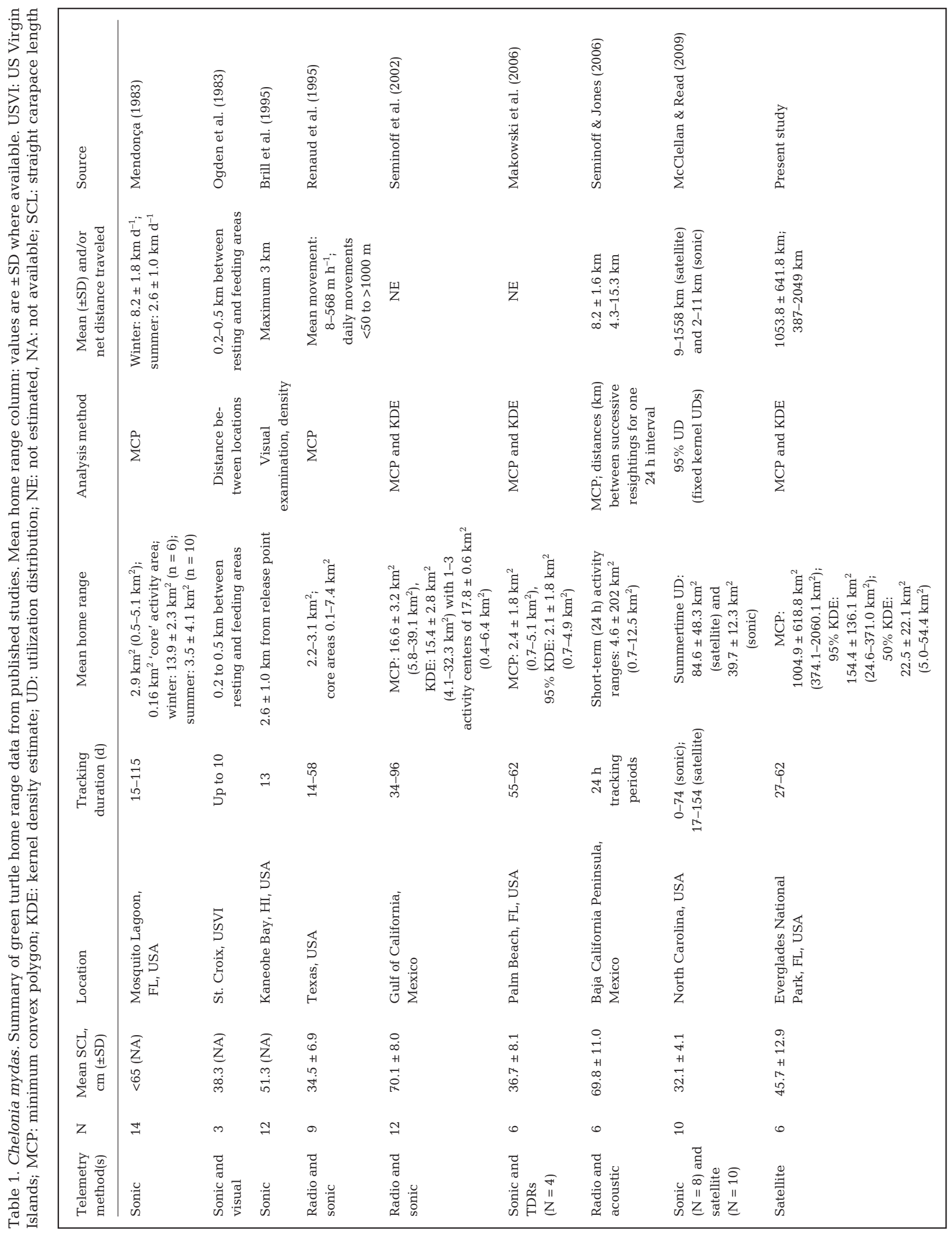


meet this objective by providing baseline information on juvenile green turtles in the southwest coastal zone of ENP.

\section{MATERIALS AND METHODS}

Study area. We conducted this study from March 2007 to June 2008 along the coastline near the Big Sable Creek (BSC) Complex, southwest coastal ENP, Florida, USA ( $25^{\circ} 16.780^{\prime} \mathrm{N}, 81^{\circ} 09.574^{\prime} \mathrm{W}$, Fig. 1). The BSC complex is a network of tidally-flooded creeks characterized primarily by mangrove forest and mudflat habitat. The mouth of the complex has areas of dense marine algae and sparse seagrass (K. Hart pers. obs.). The complex is located approximately $5 \mathrm{~km}$ north of the Cape Sable beaches (Fig. 1) and just south of the entrance to the Little Shark River. The coastal shoreline and the BSC complex are dominated by red mangroves Rhizophora mangle, although white Laguncularia racemosa and black mangroves Avicennia germinans are found in almost equal abundance in the interior mangrove stands (Smith et al. 2009) at BSC. The area searched for juvenile green turtles included creeks in the northern half of the BSC site which

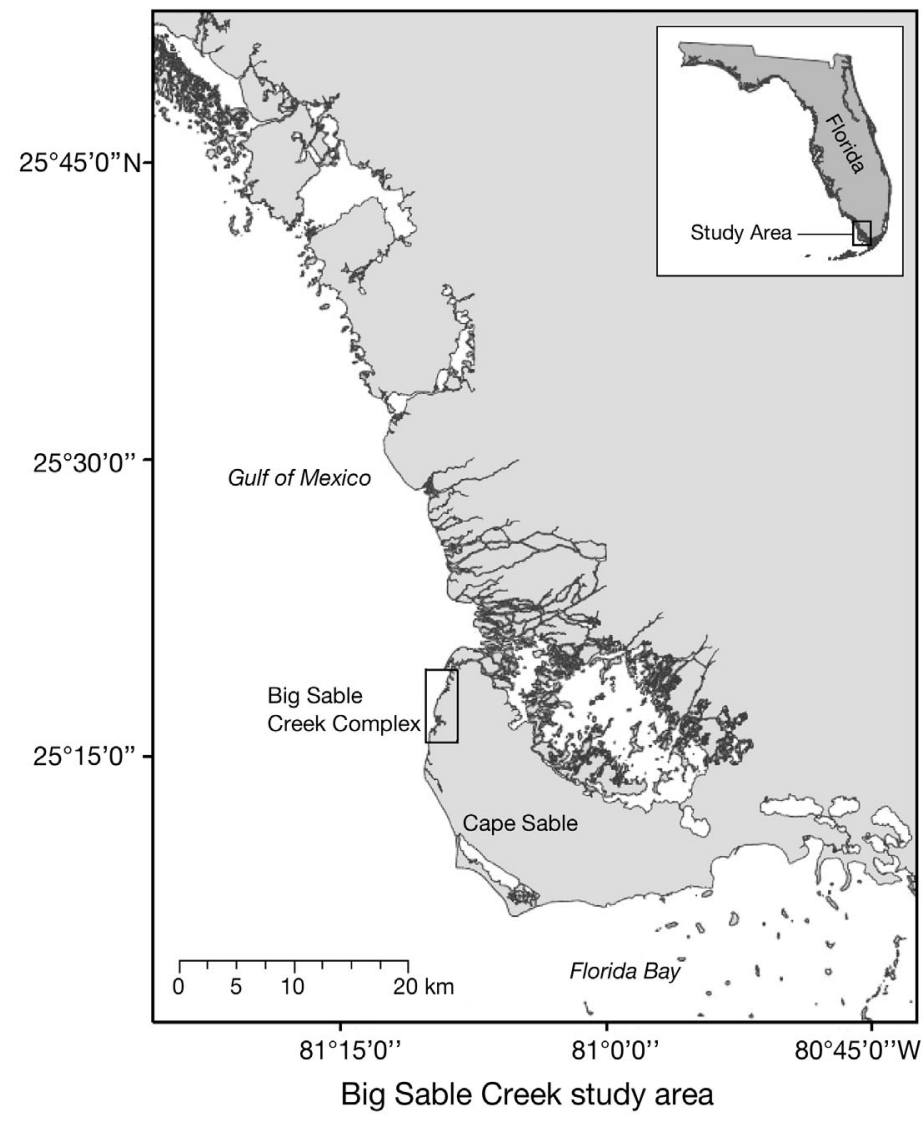

Fig. 1. Everglades National Park, southwest Florida, USA, with Big Sable Creek study site in inset extend as far as $1.2 \mathrm{~km}$ upstream from the coast and coastal areas to the north and south of the complex, covering approximately $10 \mathrm{~km}$ of shoreline. The study area is completely within the protected wilderness area of the southwest coastal Everglades. Maximum tidal range in BSC on spring tides is approximately $2.5 \mathrm{~m}$, and tides in this complex are semi- diurnal, with saline gulf waters penetrating into headwater streams (Morisawa 1968, H. R. Wanless \& B. Vlaswinkle unpubl.) on high tides. The site is a mosaic of intertidal mudflats and mangrove forests dissected by subtidal creeks. Lack of detectable freshwater inflow results in near-marine salinities (27.7 to $34.2 \mathrm{ppt}_{\text {; }}$ Silverman 2006) year-round.

Captures. We conducted dip-netting activities at night primarily around new moons and during low tides, using high-powered (3000000 candle power) lightweight spotlights while searching for turtles on a $5.8 \mathrm{~m}$ Carolina skiff fitted with a $115 \mathrm{hp}$ outboard motor. We also deployed a tangle net during the day from the skiff. The tangle net was $\sim 180 \mathrm{~m}$ long and $3 \mathrm{~m}$ deep, constructed with a braided polypropylene top line and a $9.1 \mathrm{~kg}$ lead core bottom line, and secured to the bottom with a $3.2 \mathrm{~kg}$ anchor attached at either end. The mesh was constructed of 18-gauge nylon twine with a knot-to-knot diameter of $30.5 \mathrm{~cm}$. We set the net and attached bullet-shaped buoys with longline clips along the top line of the net at 7 to $10 \mathrm{~m}$ intervals. The buoys moved vertically to indicate that something was captured in the net or that the net was snagged on some woody debris on the bottom. We checked the net at intervals of $30 \mathrm{~min}$ or less, or whenever something appeared to be entangled in it. If marine mammals were present in the area, we removed the net from the water until they left the area. We retrieved entangled turtles from the net with a dip net for backup, to avoid escape, and carefully worked out entangled bycatch (e.g. various species of sharks, endangered sawfish Pristis pectinata), checking all animals for tags, and when possible, photographing the animals. Our methods of setting and checking the tangle net were similar to those used by Ehrhart \& Ogren (1999).

Upon capture, each turtle was placed in its own plastic rectangular cement-mixing tub and kept wet. This capture method has been shown to be safe for juvenile turtles in a number of previous studies (Schmid 1998, Ehrhart \& Ogren 1999). We covered the eyes of each turtle with a wet towel, and returned them to the US Geological Survey research houseboat where we carefully transferred the turtles in their tubs to be processed for measurements and biological samples.

Standard turtle workup procedure. As part of the standard workup procedure for each turtle, we followed established protocols (NMFS SEFSC 2008). We individually marked each animal by inserting a pas- 
sive integrated transponder (PIT) tag in the right shoulder region and affixing individually numbered flipper tags to each of the rear flippers. Immediately after marking each animal, we took standard carapace measurements including curved (CCL) and straight (SCL) carapace lengths. We weighed turtles with a spring scale and netting to the nearest $0.1 \mathrm{~kg}$. Additionally, we photographed each turtle to document carapace and skin anomalies. We released all turtles at the site of capture within $2 \mathrm{~h}$.

Satellite telemetry. We selected 6 juvenile green turtles in good condition (i.e. not emaciated, with fewer than 3 external fibropapillomas [FPs], each less than $2 \mathrm{~cm}$ in diameter) for tracking after capture in the southwest coastal Everglades. We included 2 FP turtles because Brill et al. (1995) found no obvious effects of movement patterns or habitat use on juvenile Hawaiian greens. Observations of these individuals $24 \mathrm{~h}$ post-tagging also indicated that they were feeding and behaving normally (i.e. swimming regularly).

We fitted a Wildlife Computers SPOT5 platform terminal transmitter (PTT) to each turtle. Each tag $(2 \times \mathrm{AA}$ model) had a saltwater switch, output of $0.5 \mathrm{~W}$, and measured $79.7 \times 49.5 \times 18.1 \mathrm{~mm}$ (length $\times$ width $\times$ height), with a mass of $95 \mathrm{~g}$ in air. We ensured that each PTT plus epoxy did not exceed $5 \%$ of the turtle's body weight; the cut-off value for tagged turtles was $>4 \mathrm{~kg}$ mass. Prior to transmitter application with PowerFast $^{\mathrm{TM}}$ 2-part marine epoxy, we removed epibionts (e.g. barnacles, algae) from the carapace of each turtle and sanded and cleaned the carapace with isopropanol. We streamlined attachment materials so that neither buoyancy nor drag would affect the turtle's swimming ability, and we minimized the epoxy footprint due to the small size of the turtles in the study. The anticipated battery life of each tag was $1 \mathrm{yr}$, and we set each tag to be active for $24 \mathrm{~h} \mathrm{~d}^{-1}$. All tagged turtles were released at or near the point of capture.

Data filtering and analysis. We used the SatelliteTracking and Analysis Tool (STAT; Coyne \& Godley 2005) to archive and filter location data. Points were grouped into location classes (LCs) according to decreasing accuracy (i.e. highest to lowest accuracy: LCs 3, 2, 1, 0, A, B, and Z). Hays et al. (2001) and Vincent et al. (2002) found that accuracy of LC A was comparable to that of LC 1 locations from Argos, so we included LC 3, 2, 1, 0, A, and B locations, but filtered out locations that fell into any of the following categories: (1) LC Z, (2) locations that required straight-line travel speeds over $5 \mathrm{~km} \mathrm{~h}^{-1}$, and (3) locations that occurred at elevations over $0.5 \mathrm{~m}$. Using ArcGIS 9.3 (ESRI 2007), we manually removed obviously erroneous points (e.g. those that 'zig-zagged' land or large areas of open water) and implausible locations that remained after the STAT filtering process.
To facilitate comparisons to other previously published studies that used radio- and sonic-tracking methods to determine home ranges, we calculated MCP estimates (Burt 1943, Mohr 1947). Home range metrics by definition describe the area traversed by an animal during normal daily activities, excluding migrations or erratic movements (Bailey 1984). Calculating a home range requires re-sightings of individuals over extended time periods (White \& Garrott 1990). Estimates of MCP identify home ranges as the area within the polygon formed by joining the outermost resighting positions of an animal (Burt 1943); this method has been commonly applied, especially in radio and sonic tracking studies on juvenile sea turtles (Table 1). However, MCP is sensitive to outlying observations and is constrained by its ability to identify fine-scale spatial use patterns within the home range boundary (White \& Garrott 1990).

To minimize autocorrelation in spatial analyses, we generated mean daily locations for each turtle from the accepted locations. The resulting coordinates provided raw data for KDE analysis across all individuals. Kernel density is a non-parametric method used to identify 1 or more areas of disproportionately heavy use (i.e. core areas) within a home range boundary (for review see Worton 1987, 1989, White \& Garrott 1990), with appropriate weighting of outlying observations. Seaman \& Powell (1996) suggested this approach as the most accurate home range assessment technique, and since then it has been used to delineate foraging grounds for several species of sea turtle (Makowski et al. 2006, Seney \& Landry 2008; our Table 1). We used the Home Range Tools for ArcGIS extension (Rodgers et al. 2005) and fixed kernel least squares cross-validation smoothing factor $\left(h_{\mathrm{CV}}\right)$ for each KDE (Worton 1995, Seaman \& Powell 1996). When the variance of $x$ and $y$ coordinates of the points were highly unequal, the data were rescaled before applying the kernel method. We used ArcGIS 9.3 to calculate the in-water area $\left(\mathrm{km}^{2}\right)$ within each contour and to plot the data. We used a $95 \% \mathrm{KDE}$ to estimate overall home range of a turtle during the springtime tracking period and a $50 \% \mathrm{KDE}$ to represent the core area of activity during this same time period (Hooge et al. 2001). We overlaid the ENP boundary on all resulting maps and summed locations with respect to the boundary. We used NOAA chart 11433 to estimate depth, since there is no available bathymetric coverage for this area.

To test for and quantify site fidelity, we used the Spatial Analyst and Animal Movement (AMAE) extension for ArcView 3.2. We used Monte Carlo Random Walk (MCRW) simulations to test for site fidelity (100 replicates), testing tracks for spatial randomness against randomly generated walks (Hooge et al. 2001, Mansfield et al. 2009). Tracks exhibiting site fidelity indicate 
that the turtles' movements were more spatially constrained compared to randomly distributed or dispersed movement data (Hooge et al. 2001). Further, to assess residency within the protected area of the park, we tested the null hypothesis that satellite-tagged juvenile greens spent an equal proportion of time (e.g. number of days) within and outside of ENP boundaries by comparing distances from shore (distance measured as negative values towards shore, positive values towards the sea) for all filtered locations in a chisquared test. We also used $t$-tests with a Satterthwaite approximation due to unequal variances to test the null hypothesis that each turtle's daytime and nighttime locations did not differ in their distance to the coastal line. We measured distance from the shoreline in ArcView. We calculated travel speed for each turtle using a linear distance between points in $\mathrm{km} \mathrm{h}^{-1}$, which was the average linear distance moved over time of 2 consecutive filtered locations. We conducted all statistical tests in SAS (SAS Institute 1996) and used an $\alpha$ level of 0.05 for all analyses.

\section{RESULTS}

\section{Turtles}

The 6 satellite-tagged juvenile greens ranged in size from 33.4 to $67.5 \mathrm{~cm}$ SCL (mean \pm SD: $45.7 \pm 12.9 \mathrm{~cm}$ ). Mass of the 7 tracked individuals ranged from 4.4 to $40.8 \mathrm{~kg}(16.0 \pm 13.8 \mathrm{~kg}$; Table 2$)$. We captured 2 of the 6 satellite-tagged turtles using dipnets at night and the remaining 4 using the tangle net during the day.

\section{Satellite tracks}

We obtained 1598 locations from the 6 satellitetagged turtles and a total of 286 PTT days. The range of days at large was 27 to $62 \mathrm{~d}(47.7 \pm 13.0 \mathrm{~d})$. Filtering by LC, travel speed, and topography resulted in 44.8 to $60.9 \%$ of locations across all turtles being retained for analysis. Across all 6 turtles, the average proportions of spatial data in each LC were 1.9 (LC3), 3.4 (LC2), 6.8 (LC1), 6.8 (LC0), 16.8 (LCA), and 65.2\% (LCB).

\section{Home range and movement}

We observed consistent use of coastal habitats by juvenile green turtles near their capture and release sites in both 2007 and 2008 (Fig. 2). Estimates of MCP area for each turtle ranged from 374.1 to $2060.1 \mathrm{~km}^{2}$ (101.3 to $184.8 \mathrm{~km}$ perimeter; Table 3). Fixed KDEs for $95 \%$ contour areas ranged from 24.6 to $371.0 \mathrm{~km}^{2}$ (mean $154.4 \pm 136.1 \mathrm{~km}^{2}$ ). The $50 \%$ contour areas ranged from 5.0 to $54.5 \mathrm{~km}^{2}$ (Table 3 ). The area representing the intersection of all turtles' $50 \%$ core areas (Fig. 3) was $3.1 \mathrm{~km}^{2}$ and was spatially similar for both 2007 and 2008. Further, water depth of each turtle's $50 \% \mathrm{KDE}$ and the intersection of all $50 \% \mathrm{KDEs}$ was $\leq 0.6 \mathrm{~m}$ mean low water.

The site fidelity test confirmed that the observed turtle tracks and movements were more constrained than random movement paths (Table 3). In all cases, $\mathrm{p}$ or the proportion of the movement paths with higher mean squared distance (MSD) values was $>98.0198$ (Table 3). Thus, we observed site fidelity in the satellite tracking data. Turtles traveled a net distance of 387 to $2049 \mathrm{~km}$ (mean $1053.8 \pm 641.8 \mathrm{~km}$ ). Mean travel speeds for tracked turtles ranged from 0.78 to $1.49 \mathrm{~km}$ $\mathrm{h}^{-1}$ (SD range 1.01-1.30). Whereas the smallest turtle (ID no. 60591, mass $4.4 \mathrm{~kg}$ ) had the lowest mean travel speed, larger turtles did not appear to swim significantly faster. However, these travel speeds should be considered approximate swim speeds, as we cannot confirm linear travel. Travel speeds (i.e. measured linear distance over time) may not equate to actual swim speeds, as swim speeds take into account directional movements, which may in fact not be linear.

Table 2. Chelonia mydas. Body size and tracking details for 6 juvenile green turtles from the southwest coastal Everglades, Florida, USA, in 2007 and 2008. SCL: straight carapace length from notch to tip; No. locations accepted: locations remaining after filtering raw Argos data as described in 'Materials and methods'

\begin{tabular}{|lccccccc|}
\hline Turtle ID & $\begin{array}{c}\text { SCL } \\
(\mathrm{cm})\end{array}$ & $\begin{array}{c}\text { Mass } \\
(\mathrm{kg})\end{array}$ & $\begin{array}{c}\text { Capture } \\
\text { method }\end{array}$ & $\begin{array}{c}\text { Date of } \\
\text { deployment }\end{array}$ & $\begin{array}{c}\text { No. days } \\
\text { tracked }\end{array}$ & $\begin{array}{c}\text { No. locations } \\
\text { received }\end{array}$ & $\begin{array}{c}\text { No. (\%) } \\
\text { locations accepted }\end{array}$ \\
\hline 60591 & 33.4 & 4.4 & Dip net & 14 March 2007 & 50 & 84 & $44(52.4)$ \\
60589 & 40.4 & 8.6 & Dip net & 14 March 2007 & 41 & 23 & $14(60.9)$ \\
55026 & 43.5 & 14.1 & Tangle net & 4 March 2008 & 60 & 516 & $231(44.8)$ \\
60590 & 35.4 & 5.8 & Tangle net & 4 March 2008 & 62 & 148 & $76(51.4)$ \\
55024 & 67.5 & 40.8 & Tangle net & 1 May 2008 & 46 & 578 & $298(51.6)$ \\
55025 & 54.1 & 22.2 & Tangle net & 3 May 2008 & 27 & 249 & $131(52.6)$ \\
\hline
\end{tabular}



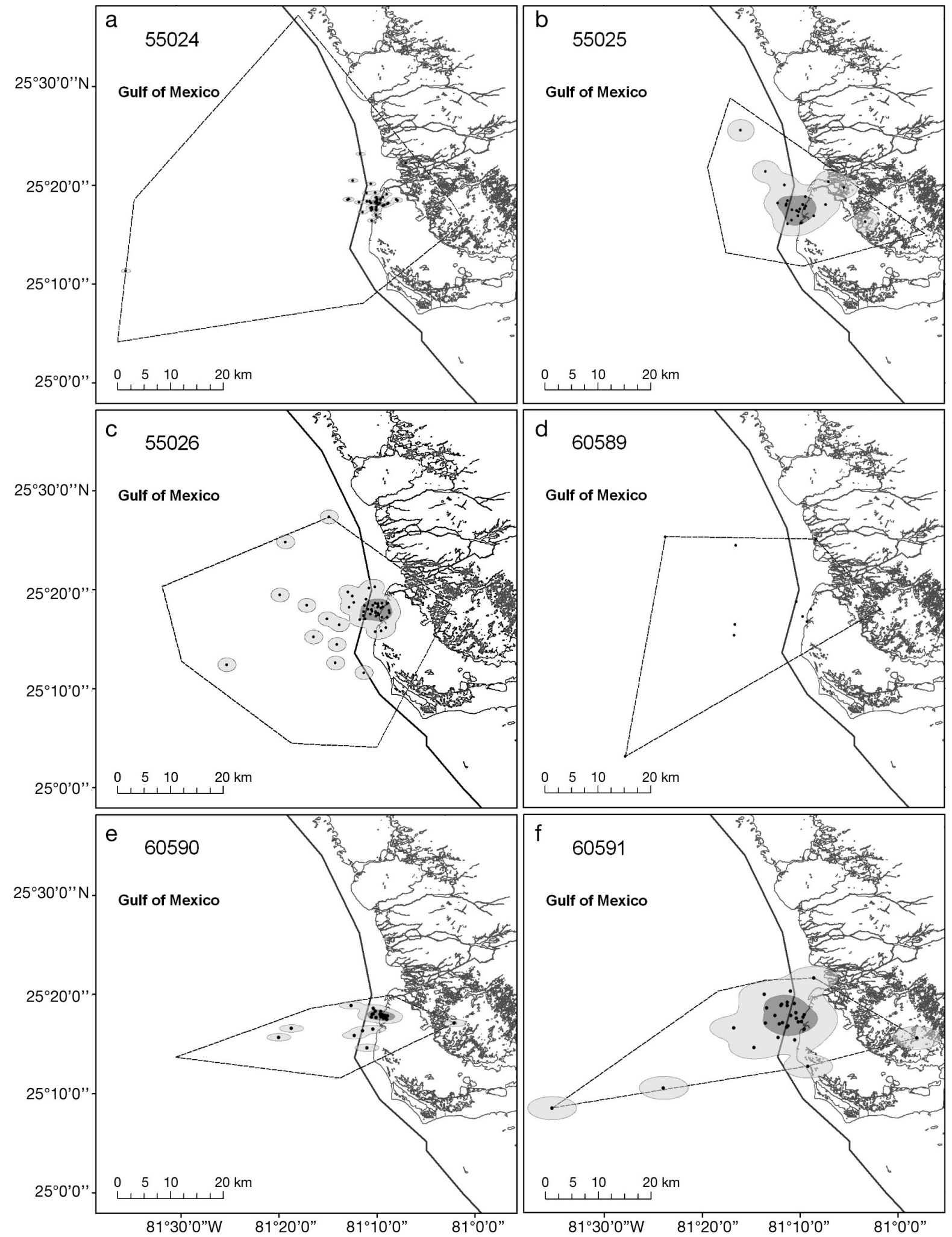

Fig. 2. Minimum convex polygon (MCP) and kernel density estimates for 6 juvenile green turtles (a-f) satellite-tracked in the Everglades National Park, southwest Florida, in 2007 and 2008. Core-use areas (50\% kernel density) are shown in dark gray, and overall home ranges (95\% kernel density) are in lighter gray. Dashed lines represent MCPs and bold lines the Everglades boundary line. Black dots represent mean daily locations (when available) for each turtle 
Table 3. Chelonia mydas. Home range and core activity areas for 6 juvenile green turtles satellite-tracked in the southwest coastal Everglades, Florida, USA, in 2007 and 2008. Home range was determined using minimum convex polygon (MCP) and kernel density estimator (KDE) methods. The specific smoothing parameter $\left(h_{\mathrm{cv}}\right)$ used for KDE estimates for each turtle's data is presented. One turtle (ID 60589) did not have enough data for KDE estimates. Site-fidelity test results report $\mathrm{p}$, the proportion of the movement paths with higher mean squared distance (MSD) values

\begin{tabular}{|c|c|c|c|c|c|c|c|c|c|c|}
\hline \multirow{2}{*}{$\begin{array}{l}\text { Turtle } \\
\text { ID } \\
60591\end{array}$} & \multirow{2}{*}{$\begin{array}{c}\begin{array}{c}\text { Tracking } \\
\text { year }\end{array} \\
2007\end{array}$} & \multirow{2}{*}{$\begin{array}{c}h_{\mathrm{cv}} \\
0.26\end{array}$} & \multirow{2}{*}{$\begin{array}{c}\begin{array}{c}\text { Track } \\
\text { duration } \\
\text { (d) }\end{array} \\
50\end{array}$} & \multicolumn{2}{|c|}{$\begin{array}{c}\text { Contour area } \\
50 \% \quad 95 \% \\
\left(\mathrm{~km}^{2}\right)\end{array}$} & \multirow{2}{*}{$\begin{array}{c}\begin{array}{c}\text { MCP } \\
\text { perimeter } \\
(\mathrm{km})\end{array} \\
137.4\end{array}$} & \multirow{2}{*}{$\begin{array}{c}\mathrm{MCP} \\
\text { area } \\
\left(\mathrm{km}^{2}\right)\end{array}$} & \multirow{2}{*}{$\begin{array}{l}\text { Site fidelity } \\
\text { test }(p)\end{array}$} & \multirow{2}{*}{$\begin{array}{c}\mathrm{MSD}\left(\mathrm{R}^{2}\right) \\
(\mathrm{km}) \\
95552.9\end{array}$} & \multirow{2}{*}{$\begin{array}{l}\text { Avg. MSD }\left(\mathrm{R}^{2}\right) \text { of } \\
\text { random movement } \\
\text { paths }(\mathrm{km})\end{array}$} \\
\hline & & & & 54.5 & 371.0 & & & & & \\
\hline 60589 & 2007 & - & 41 & - & - & 135.9 & 964.4 & $>98.0198$ & 230375.2 & 1452359.5 \\
\hline 55026 & 2008 & 0.21 & 60 & 18.7 & 148.9 & 140.7 & 1360.8 & $>99.0099$ & 52744.4 & 2717534.9 \\
\hline 60590 & 2008 & 0.20 & 62 & 6.9 & 54.7 & 101.3 & 374.1 & $>99.0099$ & 37071.6 & 1178531.3 \\
\hline 55024 & 2008 & 0.53 & 46 & 5.0 & 24.6 & 184.8 & 2060.1 & $>99.0099$ & 39158.8 & 2120328.4 \\
\hline 55025 & 2008 & 0.32 & 27 & 27.4 & 172.8 & 106.7 & 608.6 & $>99.0099$ & 34908.2 & 1055703.9 \\
\hline
\end{tabular}

We detected no difference in diurnal patterns of time that turtles spent closer to the coast or farther out in deeper or open water. Daytime and nighttime locations and their respective distance from shore for each turtle showed no significant differences for any of the 6 turtles ( $\mathrm{p}>0.1$ in all cases; ID no. 55024: $t_{296}=0.28, \mathrm{p}=$ 0.778; ID no. 55025: $t_{129}=0.65, \mathrm{p}=0.517$; ID no. 55026: $t_{229}=-1.23, \mathrm{p}=0.219 ;$ ID no. 60589: $t_{12}=0.34, \mathrm{p}=0.742$; ID no. 60690: $t_{57}=1.65, \mathrm{p}=0.104$; ID no. 60591: $t_{18}=$ $-0.32, p=0.752$ ). However, chi-squared results indicated that 4 of 6 turtles (i.e. those that were tracked in 2008) spent a significant proportion of time within the boundaries of ENP (ID no. 55024: $\chi^{2}{ }_{1}=41.09$, p < 0.0001; ID no. 55025: $\chi_{1}^{2}=21.16, \mathrm{p}<0.0001$; ID no. 55026: $\chi^{2}{ }_{1}=23.13, \mathrm{p}<0.0001$; ID no. 60589: $\chi^{2}{ }_{1}=0.09$, $\mathrm{p}=0.763$; ID no. 60590: $\chi^{2}{ }_{1}=22.15, \mathrm{p}<0.0001$; ID no. 60591: $\chi^{2}{ }_{1}=0.807, \mathrm{p}=0.369$ ).

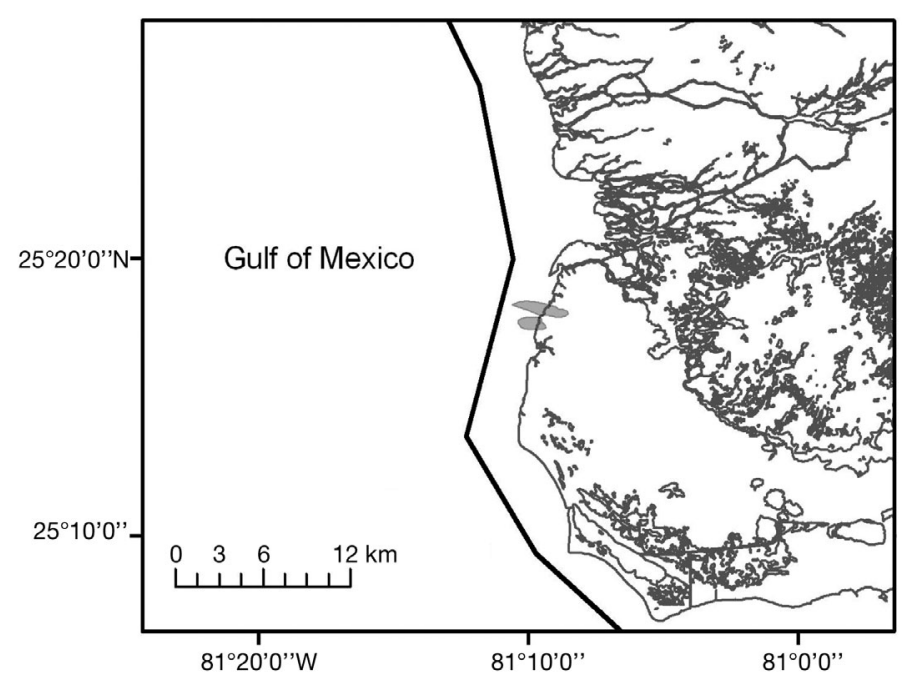

Fig. 3. Overlap of all $50 \%$ fixed kernel densities (grey patches) for satellite-tracked juvenile green turtles in the Everglades National Park (ENP), southwest Florida. Bold black line represents the ENP boundary

\section{DISCUSSION}

We provide the first estimates of juvenile green turtle core activity areas in the Everglades. We observed fidelity to the capture and release site for all 6 individuals in the spring over 2 different years; these observations are consistent with reports from other green turtle foraging grounds that documented juvenile green turtle affinity with areas characterized by marine algae patches (Ogden et al. 1983, Seminoff et al. 2002). Our data suggest that the marine algal pastures along the shallow-water margins of the study area are epicenters of juvenile green sea turtle activity. Our data also indicated that turtles visited mid-bay and insular habitats such as Whitewater Bay (Fig. 2), although they spent less time in such habitats than in the vicinity of the coastal capture and release sites. The microhabitat features of this core-use area (i.e. shallow cove with abundant sources of marine algae and dead mangrove logs that provide refuge sites from predators) may indicate important characteristics that are optimal for juvenile green turtles along the southwest Florida coast. Where these features are present along this coast and elsewhere in the Everglades, we may find additional groups of small juvenile green turtles.

Our tracking efforts delineated home ranges and quantified site fidelity for juvenile green turtles in the Everglades, indicating resident-type behavior for these 6 turtles. These results support the hypothesis that by establishing a core use area or home range, juveniles may enhance their access to resources that offer the most benefit for their growth to sexual maturity (Limpus \& Walter 1980, Limpus et al. 1994, Makowski et al. 2006). The individual home ranges for juvenile green turtles in ENP in the spring are consistent with those derived from earlier radio and sonic-tracking studies of the behavior and ecology of juvenile green turtles in neritic, shallow-water, inshore feeding grounds in other locations in Florida and elsewhere (Table 1). 
We obtained 286 total PTT days in this study, which is far fewer than the 728 tracking days reported by Seminoff et al. (2002) but comparable to both Mendonça's (1983) study that lasted 199 d and Makowski et al.'s (2006) 120 d tracking study. McClellan \& Read (2009) also obtained similar tracking durations for juvenile greens of approximately the same size as the Everglades turtles (Table 1). Our tracking durations are most similar to those reported by Renaud et al. (1995), who radio- and sonic-tracked 9 green turtles ( 29.1 to $47.9 \mathrm{~cm} \mathrm{SCL}, 2.6$ to $14.8 \mathrm{~kg}$ ) in Texas, USA, from 14 to $58 \mathrm{~d}$, and the more recent study by McClellan \& Read (2009), who sonic- and satellite-tracked 10 green turtles of 27.9 to $42.5 \mathrm{~cm}$ SCL for 17 to $154 \mathrm{~d}$ in North Carolina, USA (Table 1). Still, compared to longer-duration studies on adult sea turtles (see Godley et al. 2008 for a review), we obtained relatively short tracking times for our turtles. This short tracking may be indicative of battery failure or tag loss. Fastgrowing juveniles may shed their scutes and the attached satellite tags much more quickly than adults, thus causing transmissions to cease prematurely. Tag shedding may also result from turtle interactions with habitat structures (i.e. vegetation, dead mangrove logs, other debris), particularly if young turtles are using habitats provided by such coarse woody debris for refuge or shelter. Future experimentation with captive greens and various tag attachment methods and materials similar to Seney et al. (2010) and Renaud et al. (1993) is warranted to determine optimal tag retention rates on juveniles over time.

Although we did not specifically test for instrument effects on each animal post-release, we did not see any difference in the timing or quality of locations obtained immediately post-release versus later during the tracking duration. We re-sighted 2 of our tagged turtles $(60589,60591)$ in the study site within 24 to $48 \mathrm{~h}$ of release, and both appeared to be feeding; thus, we assumed the tag effect was minimal. Watson \& Granger (1998) previously tested for a hydrodynamic effect of a satellite transmitter on a model juvenile green turtle and found that a carapace-mounted transmitter increased drag by 27 to $30 \%$ and effectively reduced swimming speed by $11 \%$. Because juvenile greens in our study appeared to be feeding and moving relatively slowly, the movements of these wild turtles may not have been affected as much as predicted by Watson \& Granger (1998).

Juvenile green turtles in the Everglades displayed fidelity to capture and release sites with limited home ranges over the course of several months in 2 successive spring seasons. These findings are consistent with previously conducted satellite telemetry studies comparing movements of juvenile greens conducted outside of Florida. Godley et al. (2003) tracked 4 tagged juveniles in coastal waters off Brazil, 2 of which displayed behaviors similar to the Everglades turtles in that they all remained near the capture/release site for extended periods. Three of the turtles in that study (turtles A, B, and C) were similar in size to our study turtles, but 2 were tracked for longer durations (i.e. 96 and 197 d). Pelletier et al. (2003) tracked 2 wild-caught green turtles in the Indian Ocean that were similar in size and displayed similar fidelity to release sites to that observed for Everglades turtles. However, habitat differences between our study and theirs (i.e. nearshore versus open ocean), may preclude comparison of the results. Most recently, McClellan \& Read (2009) tagged juvenile greens very close in size to those captured in the Everglades, and they obtained tracking durations and observed net distances traveled per individual that were similar to our observations (Table 1). Also, McClellan \& Read (2009) determined summertime utilization distributions (UDs) for North Carolina greens as $84.6 \pm 48.3 \mathrm{~km}^{2}$ based on satellite tracking. This estimate falls between our observations of the mean $50 \%$ core use area $\left(\mathrm{KDE}_{3} 22.5 \pm 22.1 \mathrm{~km}^{2}\right)$ and the mean general use area $\left(95 \% \mathrm{KDE}_{;} 154.4 \pm\right.$ $136.1 \mathrm{~km}^{2}$ ). That these 2 independent measures of seasonal home ranges are so similar in mangrove (present study) versus salt marsh (McClellan \& Read 2009) habitat is striking, perhaps reflecting limits to home range area for this size class of green turtles.

However, questions remain as to the possibility of seasonal shifts in turtle habitat use within ENP because of the relatively short tracking duration in this study. Whether juvenile green turtle habitat-use patterns change in this area following the passage of summer tropical storms and hurricanes should be evaluated. Such storms generate tremendous wave and wind energy and have the potential to change shoreline topography and cover, dislodge marine algae, and change microhabitat features of the shoreline.

Our data show that the spatial location of the combined 2007 and $200850 \%$ core use areas (Fig. 3) is similar, perhaps suggesting that that there may be key microhabitat features of the site that make that area particularly suitable for juvenile greens either as a foraging area or a refuge site. An acoustic tracking study with deployment of a network of stationary receivers along the coastline may allow for longer tracking durations of individual turtles, which would help elucidate the extent of areas used by turtles at specific times of the year. An exploration of seasonal changes in habitat use, especially in areas where CERP activities are planned, would be valuable as a future study in this area.

Although we did not observe a difference in diurnal patterns of habitat use by juvenile green turtles in the coastal zone versus deeper water habitats (i.e. different distances from shore), it is possible that using satel- 
lite telemetry prevented us from capturing the finescale movements reported by Ogden et al. (1983) and Mendonça (1983) in their radio- and sonic-tracking studies of behavior and ecology of juvenile green turtles at other neritic, shallow-water, inshore feeding grounds. Ogden et al. (1983) conducted observations plus acoustic tracking to document diel foraging patterns of juvenile greens in St. Croix, US Virgin Islands. Similarly, Mendonça (1983) showed that green turtles in Florida fed on seagrass flats in mid-morning and mid-afternoon, then moved into deeper water during mid-day hours for resting. In the Everglades it is possible that turtle forage resources and ideal resting sites may be in the shallow coastal zone and that larger predators (i.e. various species of sharks) await the turtles in deeper habitat. However, to explore these finerscale movement questions in this study site, focused, short-term radio and sonic tracking techniques should be employed.

Core activity areas generated from filtered data indicate relatively restricted, nearshore movement among juveniles during the springtime tracking period. This restricted movement implies a strong fidelity to the southwest coastal Everglades. The springtime home ranges of green turtles were extremely small, and individual turtles were located on successive days within the same coastal embayments or tidal creeks, a pattern that is consistent with other studies of green turtles on the east coast of the US (Mendonça 1983, McClellan \& Read 2009). Mendonça (1983) reported that turtles tracked in an east coast Florida lagoon returned to resting sites within $3 \mathrm{~m}$ of their previous night's location. Although we did not observe differences in daytime versus nighttime distributions of satellite locations with respect to distance to shore, our results suggest that Everglades juvenile greens display similarly strong site fidelity especially to tidal creeks and embayments along the mangrove coastline.

Foraging optimality models suggest that animals will select resources of higher quality over those of lower quality (Krebs \& Davies 1993, Bjorndal 1997, Gilbert 1998). In our study, we observed juvenile green turtles foraging in habitats with abundant patches of Chlorophyta and Rhodophyta; thus we hypothesize that these marine algae pastures may be more important than seagrass-dominated habitats as forage resources for juvenile green turtle populations in ENP or southwest Florida. When animals encounter areas of sufficiently abundant prey or sufficient resources for forage, they often engage in area-restricted searches by decreasing their travel rate and/or increasing their turning frequency and angle (Turchin 1991). Conversely, animals encountering unsuitable habitat often have fast travel rates and infrequent and small turning angles (Turchin 1991). We measured relatively small core activity areas, with site fidelity for all turtles and overlap of core areas used by individual turtles over a range of juvenile sizes in different years; all turtles also showed relatively slow travel speeds, similar to those reported by Seminoff \& Jones (2006) (0.18 to $0.64 \mathrm{~km} \mathrm{~h}^{-1}$ ). Thus, we surmise that juvenile greens tracked in this study displayed area-restricted search patterns, as well as behavior typical of resident turtles.

\section{CONCLUSIONS AND MANAGEMENT RECOMMENDATIONS}

Our study has documented habitat use by juvenile green turtles in the mangroves of southwest Florida, a site not previously recognized as important for this endangered species. Because very little information is available globally for juvenile greens, this study represents an important contribution to data on sites in the USA that may serve as refuges and developmental habitat for these endangered sea turtles. Although it remains to be seen whether these juvenile green sea turtles are resident for longer than $62 \mathrm{~d}$ in this particular site, we observed considerable fidelity to capture and release sites among all individuals. We have also logged many sightings of juvenile greens in the study area since 2001 (K. Hart unpubl. data). Additional tracking of long-term (i.e. over the next several years) residence patterns of these turtles may help to elucidate the importance of this study site for other juvenile greens.

The results of our study also underscore the need to consider the impacts of Everglades restoration activities on juvenile green turtles and their habitat. Whether restoration of large coastal areas near the Everglades affects green turtles living downstream of construction activities and making use of coastal seagrass and marine algal resources remains to be seen. Characterization of marine turtle aggregations in the coastal zone likely to be impacted by restoration activities will allow for determination of how changes in hydrology affect the distribution and viability of juvenile green turtles and the seagrass and marine algal resources upon which they rely for food. Results of such a study could inform decision-makers about the effects of various freshwater release patterns to the coastal zone, as well as provide much-needed data for the Atlantic Green Turtle Recovery Plan (NMFS \& USFWS 1991). If juvenile greens in other areas of the coastal zone of southwest Florida behave similarly to the juvenile greens tracked in this study, we may expect them to exhibit residence very close to the capture and release sites, in shallow depths, and in areas with dense patches of marine algae and sparse seagrass. 
Determining the distribution and seasonal movements for all life stages of Chelonia mydas in the marine environment has been identified by the US Fish and Wildlife Service and the National Marine Fisheries Service as necessary to achieve recovery of the population of US Atlantic green turtles (NMFS \& USFWS 1991). Decisions regarding restoration efforts in coastal areas of the Everglades that could serve as important developmental habitat for juvenile green turtles must take into account likely effects on forage resources found in those habitats. In order to conserve marine turtles, it is necessary to know more about their spatial patterns of habitat use at various life stages, as well as about the way these patterns vary among life stages.

Acknowledgements. We acknowledge the use of STAT at www.seaturtle.org and thank the USFWS Vero Beach Office for funding. We thank A. Brame, N. Silverman, B. Reynolds, G. Hill, K. Neely, K. Ludwig, J. Sanford, C. Dufore, A. Sartain, and E. Rulison for assistance in the field. We appreciate training received from L. Erhardt and his crew at the University of Central Florida (UCF), C. McClellan at Duke, and B. Redfoot at UCF. All work was conducted according to permit guidelines and rules and regulations of the National Marine Fisheries Service (NMFS), the State of Florida Marine Turtle Program, and ENP. Finally, we thank P. Walker at ENP, P. Opay and K. Swails at NMFS, and M. Koperski at the Florida FWCC for permits. All research on juvenile green sea turtles was conducted in accordance with institutional, national, and international guidelines concerning the ethical use of animals in research and the sampling of endangered species. This research was authorized by NMFS Scientific Research Permit no. 1541, Everglades Scientific Research Permit EVER-2006SCI-0003, and State of Florida Marine Turtle Permit 176. Any use of trade, product, or firm names is for descriptive purposes only and does not imply endorsement by the US Government.

\section{LITERATURE CITED}

Bailey JA (1984) Principles of wildlife management. WileyLiss, New York, NY

Bjorndal KA (1980) Nutrition and grazing behavior of the green turtle Chelonia mydas. Mar Biol 56:147-154

Bjorndal KA (1997) Foraging ecology and nutrition of sea turtles. In: Lutz PL, Musick JA (eds) The biology of sea turtles. CRC Press, Boca Raton, FL, p 199-232

Bjorndal KA, Bolten AB, Chaloupka MY (2003) Survival probability estimates for immature green turtles Chelonia mydas in the Bahamas. Mar Ecol Prog Ser 252:273-281

Bolten AB (2003) Variation in sea turtle life history patterns: neritic vs. oceanic. In: Lutz PL, Musick JA, Wyneken J (eds) The biology of sea turtles, Vol 2. CRC Press, Boca Raton, FL, p 243-258

Bresette M, Gorham J (2001) Growth rates of juvenile green turtles (Chelonia mydas) from the Atlantic coastal waters of St. Lucie County, Florida, USA. Mar Turtle Newsl 91:5-6

Bresette M, Gorham J, Peery B (1998) Site fidelity and size frequencies of juvenile green turtles (Chelonia mydas) utilizing near shore reefs in St. Lucie County, Florida. Mar Turtle Newsl 82:5-7
Brill RW, Balazs GH, Holland KN, Chang RKC, Sullivan S, George JC (1995) Daily movements, habitat use, and submergence intervals of normal and tumor-bearing juvenile green turtles (Chelonia mydas L.) within a foraging area in the Hawaiian islands. J Exp Mar Biol Ecol 185:203-218

Burt WH (1943) Territoriality and home range concepts as applied to mammals. J Mammal 24:346-352

Campbell CL (2005) Survival probability estimates for large juvenile and adult green turtles (Chelonia mydas) exposed to an artisanal marine turtle fishery in the western Caribbean. Herpetologica 61:91-103

Carr A (1987) New perspectives on the pelagic stage of sea turtle development. Conserv Biol 1:103-121

Carr A, Meylan AB (1980) Evidence of passive migration of green turtle hatchlings in sargassum. Copeia 1980: 366-368

Coyne MS, Godley BJ (2005) Satellite Tracking and Analysis Tool (STAT): an integrated system for archiving, analyzing and mapping animal tracking data. Mar Ecol Prog Ser 301: $1-7$

Ehrhart LM, Ogren LH (1999) Studies in foraging habitats: capturing and handling turtles. In: Eckert KL, Bjorndal KA, Abreu-Grobois FA, Donnelly M (eds) Research and management techniques for the conservation of sea turtles. IUCN/SSSC Marine Turtle Specialist Group Publ No. 4

Ehrhart LM, Redfoot WE (1992) Trends in loggerhead and green turtle population densities in Florida's east coast lagoons: the usefulness of CPUE analysis. Fla Sci 55:25

Ehrhart LM, Redfoot WE, Bagley DA (2007) Marine turtles of the central region of the Indian River Lagoon System, Florida. Fla Sci 70:415-434

Environmental Systems Research Institute (ESRI) (2007) ArcGIS 9.3 GIS. Redlands, CA

Gilbert EI (1998) Juvenile green turtle (Chelonia mydas) foraging ecology: feeding selectivity and forage nutrient analysis. MS thesis, University of Central Florida, Orlando, FL

Godley BJ, Lima EHSM, Akesson S, Broderick AC and others (2003) Movement patterns of green turtles in Brazilian coastal waters described by satellite tracking and flipper tagging. Mar Ecol Prog Ser 253:279-288

Godley BJ, Blumenthal JM, Broderick AC, Coyne MS, Godfrey MH, Hawkes LA, Witt MJ (2008) Satellite tracking of sea turtles: Where have we been and where do we go next? Endang Species Res 4:3-22

Groombridge B (1982) IUCN Amphibia-Reptilia red data book. Part I: Testudines, Crocodylia, Rhynchocephalia. IUCN, Gland

Groombridge B, Luxmoore R (1989) The green turtle and hawksbill (Reptilia: Cheloniidae): world status, exploitation and trade. Secretariat of the Convention on International Trade in Endangered Species of Wild Fauna and Flora, Lausanne

> Hays GC, Åkesson S, Godley BJ, Luschi P, Santidrian P (2001) The implications of location accuracy for the interpretation of satellite tracking data. Anim Behav 61:1035-1040

Hooge PN, Eichenlaub W, Hooge ER (2001) Animal movement 2.5. US Geological Survey, Alaska Biological Science Center, Anchorage, AK

Krebs JR, Davies NB (1993) An introduction to behavioural ecology. Blackwell Science, Oxford

Kubis S, Chaloupka M, Ehrhart L, Bresette M (2009) Growth rates of juvenile green turtles Chelonia mydas from three ecologically distinct foraging habitats along the east central coast of Florida, USA. Mar Ecol Prog Ser 389:257-269 
Limpus CJ, Walter DG (1980) The growth of immature green turtles (Chelonia mydas) under natural conditions. Herpetologica 36:162-165

Limpus CJ, Couper PJ, Reed MA (1994) The green turtle Chelonia mydas in Queensland: population structure in a warm temperate feeding area. Mem Queensl Mus 35: 139-154

Makowski C, Seminoff JA, Salmon M (2006) Home range and movements of juvenile Atlantic green turtles (Chelonia mydas L.) on shallow reef habitats in Palm Beach, Florida, USA. Mar Biol 148:1167-1179

Mansfield KL, Saba VS, Kenaith JA, Musick JA (2009) Satellite tracking reveals a dichotomy in migration strategies among juvenile loggerhead turtles in the Northwest Atlantic. Mar Biol 156:2555-2570

McClellan CM, Read AJ (2009) Confronting the gauntlet: understanding incidental capture of green turtles through finescale movement studies. Endang Species Res 10:165-179

Mendonça MT (1983) Movements and feeding ecology of immature green turtles (Chelonia mydas) in a Florida lagoon. Copeia 1983:1013-1023

Mohr CO (1947) Table of equivalent populations of North American small mammals. Am Midl Nat 37:223-249

Morisawa M (1968) Streams: their dynamics and morphology. McGraw-Hill, New York, NY

Musick JA, Limpus CJ (1997) Habitat utilization and migration in juvenile sea turtles. In: Lutz PL, Musick JA (eds) The biology of sea turtles. CRC Press, Boca Raton, FL, p 137-165

NMFS \& USFWS (National Marine Fisheries Service and US Fish and Wildlife Service) (1991) Recovery plan for U.S. population of Atlantic green turtle. NMFS, Washington, DC

NMFS SEFSC (Southeast Fisheries Science Center) (2008) Sea turtle research techniques manual. NOAA Tech Memo NMFSSEFSC-579, Washington, DC

Ogden JC, Robinson L, Whitlock K, Daganhardt H, Cebula R (1983) Diel foraging patterns in juvenile green turtles (Chelonia mydas L.) in St. Croix United States Virgin Islands. J Exp Mar Biol Ecol 66:199-205

Pelletier D, Roos D, Ciccione S (2003) Oceanic survival and movements of wild and captive-reared immature green turtles (Chelonia mydas) in the Indian Ocean. Aquat Living Resour 16:35-41

Plotkin P (2003) Adult migrations and habitat use. In: Lutz PL, Musick JA, Wyneken J (eds) The biology of sea turtles, Vol 2. CRC Press, Boca Raton, FL, p 225-242

Renaud ML, Gitschlag GR, Hale JK (1993) Retention of imitation satellite transmitters fiberglassed to the carapace of sea turtles. Herpetol Rev 24:94-99

Renaud ML, Carpenter JA, Wiliams JA, Manzella-Tirpak SA (1995) Activities of juvenile green turtles, Chelonia mydas, at a jettied pass in south Texas. Fish Bull 93:586-593

Rodgers AR, Carr AP, Smith L, Kie JG (2005) HRT: Home Range Tools for ArcGIS. Ontario Ministry of Natural Resources, Centre for Northern Forest Ecosystem Research, Thunder Bay

SAS Institute (1996) A guide to statistical and data analysis using JMP and JMP IN software. Duxbury Press, Belmont, NY

Editorial responsibility: Jeffrey Seminoff,

La Jolla, California, USA
Schmid JR (1998) Marine turtle populations on the west-central coast of Florida: results of tagging studies at the Cedar Keys, Florida, 1986-1995. Fish Bull 96:589-602

Seaman DE, Powell RA (1996) An evaluation of the accuracy of kernel density estimators for home range analysis. Ecology 77:2075-2085

Seminoff JA, Jones TT (2006) Diel movements and activity ranges of green turtles (Chelonia mydas) at a temperate foraging area in the Gulf of California, Mexico. Herpetol Conserv Biol 1:81-86

Seminoff JA, Resendiz A, Nichols WJ (2002) Home range of green turtles Chelonia mydas at a coastal foraging area in the Gulf of California, Mexico. Mar Ecol Prog Ser 242: 253-265

Seney E, Landry AM Jr (2008) Movements of Kemp's ridley sea turtles nesting on the upper Texas coast: implications for management. Endang Species Res 4:73-84

Seney EE, Higgins BM, Landry AM Jr (2010) Satellite transmitter attachment techniques for small juvenile sea turtles. J Exp Mar Biol Ecol 384:61-67

Silverman NL (2006) Assessing the consequences of hurricane-induced fragmentation of mangrove forest on habitat and nekton in Big Sable Creek, Florida. MS thesis, University of South Florida, St. Petersburg, FL

Smith TJ III, Anderson GH, Balentine K, Tiling G, Ward GA, Whelan KRT (2009) Cumulative impacts of hurricanes on Florida mangrove ecosystems: sediment deposition, storm surges and vegetation. Wetlands 29:24-34

Turchin P (1991) Translating foraging movements in heterogeneous environments into the spatial distribution of foragers. Ecology 72:1253-1266

US Army Corp of Engineers and South Florida Water Management District (2004) Comprehensive Everglades restoration plan, Picayune Strand restoration (formerly Southern Golden Gate Estates ecosystem restoration). Final integrated project implementation report and environmental impact statement

> Vincent C, McConnell BJ, Ridoux V, Fedak MA (2002) Assessment of Argos location accuracy from satellite tags deployed on captive gray seals. Mar Mamm Sci 18: 156-166

Watson KP, Granger RA (1998) Hydrodynamic effect of a satellite transmitter on a juvenile green turtle (Chelonia mydas). J Exp Biol 201:2497-2505

White GC, Garrott RA (1990) Analysis of wildlife radiotracking data. Academic Press, New York, NY

Witzell WN, Schmid JR (2004) Immature sea turtles in Gullivan Bay, Ten Thousand Islands, southwest Florida. Gulf Mex Sci 2004:54-61

> Worton BJ (1987) A review of models of home range for animal movement. Ecol Model 38:277-298

- Worton BJ (1989) Kernel methods for estimating the utilization distribution in home-range studies. Ecology 70 : 164-168

> Worton BJ (1995) Using Monte Carlo simulation to evaluate kernel-based home range estimators. J Wildl Manag 59: $794-800$

Submitted: August 31, 2009; Accepted: April 8, 2010

Proofs received from author(s): May 8, 2010 